\title{
Applications of Unmanned Aerial Systems in Agricultural Operation Management: Part II: Platforms and Payloads ${ }^{1}$
}

\author{
Aditya Singh and James Fletcher ${ }^{2}$
}

Unmanned aerial systems (UASs, UAVs, or drones) have emerged as an important tool for farmers, Extension agents, and landowners to map, monitor, and manage their properties. While commercial off-the-shelf (COTS) UASs have seen major improvements in usability, practical tradeoffs between platform configurations and sensor combinations are not always clear. This EDIS document provides an overview of the primary components of typical UASs to help growers, landowners, and/or Extension agents who want to configure and/or purchase a UAS or sensor system for agricultural operations. This document is one of a threepart series focusing on the applications, configuration, and best practices for using UASs in agricultural operations management.

\section{Introduction}

Any UAS needs a minimum set of components to be operable and to collect imaging and/or sensing data for agricultural or forest management uses. The main components include the airframe or flight platform, the propulsion system, the flight controller, a geographical positioning system (GPS), some combination of sensors, and other sets of systems that are useful for safe flight (such as landing or object avoidance sensors). While sensors and safety systems are in general configurable, the flight platform determines overall flight characteristics, and in combination with the flight controller, determines the flying experience and efficiency of UAS operations. Figure 1 shows a commandand-control schematic of a typical UAS platform. The sections below outline the main components and present an overview of the variations in most commercial off-the-shelf flight packages available as of December 2020.

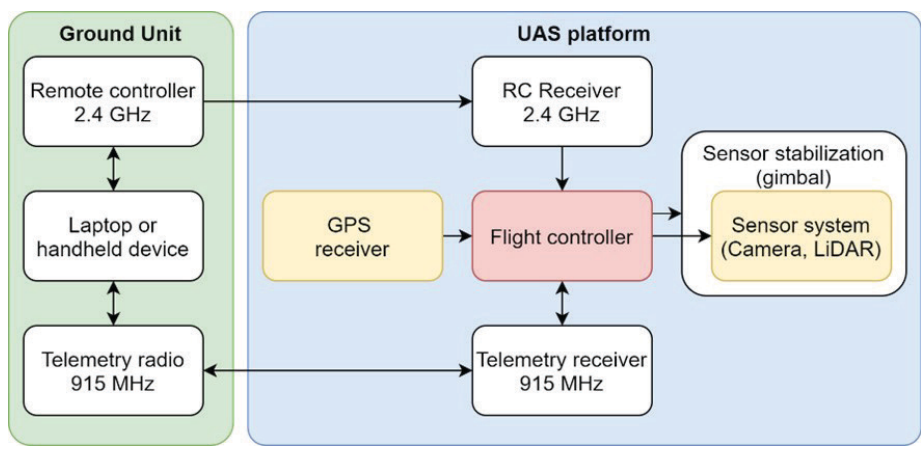

Figure 1. Command-and-control schematic of a typical unmanned aerial system.

Credits: Aditya Singh, UF/IFAS

\section{Platform}

This is the "body" of the aircraft that carries the flight controller, cameras and sensors, power supplies, propulsion mechanisms, and optional electronic components, such as GPS units. Platforms typically consist of one of the following:

1. This document is AE552, one of a series of the Department of Agricultural and Biological Engineering, UF/IFAS Extension. Original publication date February 2021. Visit the EDIS website at https://edis.ifas.ufl.edu for the currently supported version of this publication.

2. Aditya Singh, assistant professor, remote sensing, Department of Agricultural and Biological Engineering; and James Fletcher, regional specialized agent IV emeritus, water resources, UF/IFAS Mid-Florida Research and Education Center; UF/IFAS Extension, Gainesville, FL 32611.

The Institute of Food and Agricultural Sciences (IFAS) is an Equal Opportunity Institution authorized to provide research, educational information and other services

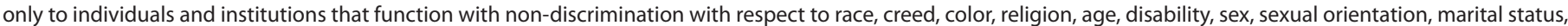

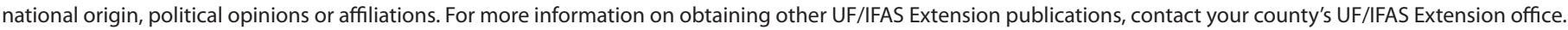
U.S. Department of Agriculture, UF/IFAS Extension Service, University of Florida, IFAS, Florida A \& M University Cooperative Extension Program, and Boards of County Commissioners Cooperating. Nick T. Place, dean for UF/IFAS Extension. 
1. Multirotor platforms that take off and land vertically and derive propulsion directly from three or more vertically aligned propellers.

2. Fixed-wing platforms that take off and land horizontally, and look and operate much like commercial aircraft, deriving lift from air driven by one or more propellers mounted horizontally along the axis of movement over conventional wings rigidly fixed to the fuselage.

3. Hybrid platforms that take off and land vertically using propellers mounted along the vertical axis but transition into horizontal flight by deriving lift from conventional wings once airborne.

Note that this is an extremely simplified list. Many combinations of flight modes exist that are available as commercial and/or experimental platforms. Table 1 compares advantages and disadvantages of flight platforms for typical users.

\section{Power Supply}

The choice of batteries or alternative power supply systems for any UAS platform is based on trade-offs in propulsion power demand, requirements of peripheral electronics or sensors, and payload capacities of the UAS. Power systems are therefore supplied as standard equipment with COTS UASs. It is generally a good idea not to switch batteries of different capacities or manufacturers and to stay within the payload capacities for which the UAS platform is designed. Increasingly, manufacturers are offering propulsion systems that are also "hybrid" in nature: these are typically configured as having a gas engine that provides the power source as well as LiPo (lithium polymer) batteries as emergency backups. These hybrid-powered UASs can lift heavier payloads ( 10-15 lb) for longer periods ( 1-3 hours).

In general, most UASs are powered by high power density rechargeable batteries. The most prevalent lithium polymer batteries (LiPo) are available in $3.7 \mathrm{~V}$ cells internally connected in serial (denoted in "S" notation, i.e., $1 \mathrm{~S}=3.7 \mathrm{~V}, 6 \mathrm{~S}$ $=3.7 \times 6=22 \mathrm{~V}$ ), and linked in parallel to produce a wide variety of capacities (amperage ratings). The amperage ratings on most LiPo batteries denote the length of time they can supply power at safe rates (in terms of current over time, $\mathrm{mAh}$ ). Most batteries also have a "C" rating, which denotes the amount of peak current that can be discharged from a battery during peak power demand. In combination, a $6 \mathrm{~S}-16,000 \mathrm{mAh} 25 \mathrm{C}$ battery can safely discharge $16 \mathrm{~A}$ of current at $22 \mathrm{~V}$ for an hour with a peak discharge capacity of $25 \times 16=320 \mathrm{~A}$. LiPo batteries are popular for their power density and number of charge-discharge cycles, but they have considerable safety issues due to a propensity to catch fire (and explode) if stored improperly. Therefore, LiPO batteries are not allowed on commercial flights in checked luggage. They should always be stored, charged, and operated with utmost care according to manufacturer specifications.

\section{Flight Controller}

This is the "brain" of the UAS. The flight controller (FC) constitutes a microcomputer that gathers attitude, altitude, and heading information from on-board magnetometers (tilt sensors), accelerometers (G-force sensors), and geographical positioning systems (GPS), and calculates aircraft heading and position data in real time to provide inputs to motors that control how and where the aircraft flies. In most cases, the FC allows tablet, smartphone, or PC-based software to upload coordinates of flight paths (also called "waypoints") that guide the platform to execute user-defined flight patterns. Almost all major UAS manufacturers bundle aircraft with their versions of FCs. In addition, the open-source hardware community has developed its own FC for a variety of flight platforms (in addition to land-based rovers and watercraft). Details are available at https://www.dronecode.org/. For users in the process of purchasing UASs, it is important to check if the FC is open-source; if not, users should find out how many programmable "waypoints" can be programmed into flight plans, and whether sensors required for the particular application are supported by the flight controller. At the broadest level, the FC monitors flight information and allows the operation of sensors at locations that are defined by the user in the flight plan. In addition, the FC supplies the geolocation from the GPS to imagery and other data collected by the sensors.

\section{Transmitter and Flight Radios}

The flight controller is generally linked to a handheld transmitter (i.e., "remote control"), typically via a $2.4 \mathrm{GHz}$ radio connection that allows the manual control of the aircraft when flying. In addition, another radio operating at $915 \mathrm{MHz}$ connects the base station (laptop computer- or cellphone-based application) with the flight controller on the UAS to exchange telemetry information (GPS location, speed, battery capacity, etc.) with the base station during operation. 


\section{Geographical Positioning System (GPS)}

The GPS unit is essentially an on-board radio receiver operating at approximately $1.3 \mathrm{GHz}$ that receives real-time signals from a constellation of navigation satellites that orbit the Earth constantly. Almost all commercially available GPS units operate based on the collection of real-time positioning signals broadcast by orbiting satellites. Satellite signals are received, parsed, compared with satellite times and the geographical position of the sensor calculated in real-time, and relayed to the flight controller. GPS units require fixes from at least four satellites to estimate their location, with a larger number of fixes generally increasing the reliability of positional estimates. In this regard, GPS units that can utilize a larger array of constellations are generally considered more stable because they can switch between constellations to maintain heading and speed. In terms of accuracy, most inexpensive GPS units $(\sim 50)$ can provide spatial positioning accuracies of 5-20 m depending on environmental conditions and satellite fixes. Users can take advantage of more recent technologies, such as realtime kinematic (RTK) or post-processed kinematic (PPK) GPS units, when higher accuracies $(\sim 2-5 \mathrm{~cm})$ are needed.

RTK systems generally involve two separate GPS units, one located on the UAS (the "rover") and a second one at the base station (a fixed position near the UAS pilot). The two GPS units communicate in real time wherein the base unit relays the satellite carrier wave to the rover, and the rover calculates the difference in the carrier signals to determine the rover's position with centimeter-scale accuracy. A PPK system works similarly, but corrections are done after the flight (hence "post-processed"). PPK systems utilize algorithms to solve for positional inaccuracies by looking at pre- and post-flight locations to arrive at globally aligned solutions that can be applied to RTK-collected data to further refine location accuracy. However, RTK systems are expensive compared to single-GPS navigation systems (single station GPS: \$50-\$100; RTK system: \$900-\$1,200).

\section{Sensor Systems}

Sensor systems can cover a wide range of applications from simple video cameras to hyperspectral and thermal imaging payloads. Table 2 gives an overview of various sensor payloads and potential applications of each.

\section{Other Critical Peripherals and/or Functions}

When using most sensor systems and payloads, especially line-scanning instruments such as hyperspectral and/or LiDAR sensors, platform stabilization assumes a critical role in obtaining useful data. The vibration in the platform can cause problems that may be compounded due to error propagation through the sensor payload. It is generally recommended that the sensor systems be mounted on a gimbal-stabilized platform that is in turn also isolated from the flight platform using vibration dampeners. To ensure consistent data acquisition, a 3D gimbal that can stabilize the sensor payload in the yaw (left-right rotation), pitch (forward-backward tilt), and roll (side-to-side tilt) axes is recommended. Note that the gimbal is an actively stabilized platform and has power requirements that need to be considered.

In addition, there are various features that can be included in the flight platform to make UASs safer and more efficient to fly and operate. These might include: sense-and-avoid sensors that use ultrasonic waves to detect obstacles and help the FC carry out evasive action; propeller guards that help avoid damage to people or equipment by physically obstructing objects from falling within the propellers' rotational orbits; automated landing gear that can be retracted while flying to give the sensor suites unobstructed view of the targets; piezometric beepers and/or LED lights as auditory or visual warning signals; and programmable "fail-safes" that ensure the UAS does not fly outside of preset flight radii or altitudes.

\section{Summary}

This document is a broad primer for Extension agents and growers who are interested in utilizing emerging and increasingly available UAS technologies. While this document is not an exhaustive list of components (as of December 2020), it is intended as a broad summary of factors that should be kept in mind when purchasing a COTS UAS. Eventually, the combination of sensors, platforms, flight controllers, and peripherals will depend on the exact application context. Readers are encouraged to contact UF/ IFAS remote sensing faculty to consult on specific needs. 
Table 1. Comparison of typical flight platforms.

\begin{tabular}{|c|c|c|c|}
\hline & & Platform Type & \\
\hline & Multirotor ${ }^{1}$ & Fixed wing ${ }^{1}$ & Hybrid $^{1}$ \\
\hline Example image & & & \\
\hline $\begin{array}{l}\text { Takeoff and landing } \\
\text { characteristics in } \\
\text { autonomous flight modes }\end{array}$ & $\begin{array}{l}\text { Predictable takeoff and landing } \\
\text { characteristics }\end{array}$ & Hard landings are common & $\begin{array}{l}\text { Moderate-high reliability } \\
\text { depending on exact configuration }\end{array}$ \\
\hline Flight time & $15-30 \mathrm{~min}$ & $\begin{array}{l}15 \mathrm{~min}-2 \mathrm{hr} \text { based on the propulsion } \\
\text { system }\end{array}$ & $\begin{array}{l}\text { Up to } 5 \mathrm{hr} \text { based on propulsion } \\
\text { system }\end{array}$ \\
\hline Ease of flying & High (with modern controllers) & $\begin{array}{l}\text { Low-moderate; requires extensive } \\
\text { training }\end{array}$ & $\begin{array}{l}\text { Variable; most systems are } \\
\text { currently in development }\end{array}$ \\
\hline $\begin{array}{l}\text { Programmed flight } \\
\text { patterns }\end{array}$ & $\begin{array}{l}\text { Precise maneuvering due to } \\
\text { hovering capability }\end{array}$ & $\begin{array}{l}\text { Best for large areas, needs to overshoot } \\
\text { areas to turn around }\end{array}$ & $\begin{array}{l}\text { Best for large areas, needs to } \\
\text { overshoot areas to turn around }\end{array}$ \\
\hline $\begin{array}{l}\text { Platform stability during } \\
\text { flight }\end{array}$ & $\begin{array}{l}\text { Low-moderate, depending on } \\
\text { design, flight controller, and } \\
\text { avionics }\end{array}$ & $\begin{array}{l}\text { Moderate-high, because of straight- } \\
\text { line flying capabilities }\end{array}$ & $\begin{array}{l}\text { Moderate-high, because of } \\
\text { straight-line flying capabilities }\end{array}$ \\
\hline Weight-flight time ratio & $\begin{array}{l}\text { High, heavy payloads usually } \\
\text { mean shorter flight times }\end{array}$ & $\begin{array}{l}\text { Low; can fly longer for the same } \\
\text { payload }\end{array}$ & $\begin{array}{l}\text { Low; can fly longer for the same } \\
\text { payload }\end{array}$ \\
\hline Cost & $\$ 500-\$ 15,000$ & $\$ 8,000-\$ 15,000$ & $\$ 8,000-\$ 200,000$ \\
\hline${ }^{1}$ Credits: Wikimedia Commons & & & \\
\hline
\end{tabular}


Table 2. Sensor systems.

\begin{tabular}{|c|c|c|c|}
\hline & Sensor & Operation & Potential Applications \\
\hline 1 & Video cameras & $\begin{array}{l}\text { Usually configured as simple three-band RGB (Red- } \\
\text { Green-Blue) imagers that obtain, store, or transmit 24-bit } \\
\text { imagery over } 5.8 \mathrm{GHz} \text { video links in variable resolutions } \\
\text { at frame rates of } 24-60 \mathrm{~Hz} \text { (frames per second). } \\
\text { Resolutions can range from } 1.2 \mathrm{MP} \text { to full-resolution (4K) } \\
\text { video depending on sensor type. Higher frame rates and } \\
\text { resolutions are generally more expensive ( } \$ 50-\$ 200) \text {. }\end{array}$ & $\begin{array}{l}\text { Obtaining real-time view of flight conditions; recording } \\
\text { capability for later use in video production. }\end{array}$ \\
\hline 2 & $\begin{array}{l}\text { RGB frame } \\
\text { cameras }\end{array}$ & $\begin{array}{l}\text { Usually three-band (RGB) imagers but configured to } \\
\text { acquire and store imagery on-board using SD cards; } \\
\text { capable of supporting much higher image resolutions } \\
\text { (as large as } 30 \mathrm{MP} \text { ). Most advanced sensors such as } \\
\text { digital single lens reflex (DSLR) cameras can store } \\
\text { imagery in raw formats that are more flexible for later } \\
\text { post-processing. Costs can range from } \$ 500-\$ 2,500 \\
\text { depending on specifications. }\end{array}$ & $\begin{array}{l}\text { Basic mapping applications: larger image sizes translate } \\
\text { into higher on-ground resolution that provides a fine- } \\
\text { scaled view of canopy structure and plot configurations. }\end{array}$ \\
\hline 3 & $\begin{array}{l}\text { Multispectral } \\
\text { cameras }\end{array}$ & $\begin{array}{l}\text { Any camera with more than three bands, typically visible } \\
\text { RGB bands extended to include a near-infrared band } \\
\text { ( } 700-1000 \mathrm{~nm} \text { ). The availability of additional bands } \\
\text { allows the creation of novel band combinations, but } \\
\text { usually comes at a cost of pixel density and therefore } \\
\text { slightly lower spatial resolution than standard RGB frame } \\
\text { cameras. Costs can range from } \$ 300-\$ 8,000 \text { depending } \\
\text { on specifications. }\end{array}$ & $\begin{array}{l}\text { Moderately advanced applications for crop } \\
\text { management; image bands can be ratioed to obtain } \\
\text { indicators of plant condition (e.g., NDVI) that are useful } \\
\text { for assessing plant health in certain conditions. }\end{array}$ \\
\hline 4 & $\begin{array}{l}\text { Hyperspectral } \\
\text { imagers }\end{array}$ & $\begin{array}{l}\text { Imagers that sample the visible and near-infrared } \\
\text { spectrum in multiple narrow wavebands (typically in } \\
5-20 \mathrm{~nm} \text { intervals). Most HS imagers (HSI) are line- } \\
\text { scanning instruments that obtain one image line at } \\
\text { a time (instead of a full-frame). Post-processing HSI } \\
\text { data typically requires custom software, good digital } \\
\text { elevation models, accurate GNSSs, and suitable } \\
\text { calibration procedures to be useful. Costs range from } \\
\$ 35,000-\$ 50,000 \text {. }\end{array}$ & $\begin{array}{l}\text { Advanced applications: can be used to detect } \\
\text { canopy nutrient status, disease incidence, and water } \\
\text { deficiencies, and to determine differences in foliar } \\
\text { biochemistry and plant performance. }\end{array}$ \\
\hline 5 & Thermal imagers & $\begin{array}{l}\text { Generally low-resolution ( } 2 \mathrm{MP} \text { ) sensors that collect } \\
\text { radiated energy in the } 7.5-12.5 \text { um spectral range } \\
\text { (thermal imagery). These sensors are generally } \\
\text { constructed using uncooled microbolometers and need } \\
\text { good internal radiometric calibrations to be useful. } \\
\text { Sensors can also typically transmit video at } 30 \mathrm{MHz} \text { or } \\
\text { store individual image frames at various rates. Costs } \\
\text { range from } \$ 5,000-\$ 15,000 \text {. }\end{array}$ & $\begin{array}{l}\text { Applications include thermography (mapping of canopy } \\
\text { temperatures); potential applications include stress } \\
\text { detection and assessment of crop water use. Data from } \\
\text { thermal sensors must be cross-validated with on-ground } \\
\text { measurements to produce accurate estimates of canopy } \\
\text { evapotranspiration. }\end{array}$ \\
\hline 6 & LiDAR sensors & $\begin{array}{l}\text { Light Detection and Ranging (LiDAR) sensors typically } \\
\text { record the reflections of laser pulses shot at targets } \\
\text { to assess the distance of the object from the sensor. } \\
\text { Data are obtained as a "cloud" of points with three- } \\
\text { dimensional location information where the laser pulses } \\
\text { bounce off targets. Costs range from } \$ 8,000-\$ 15,000 \text {. }\end{array}$ & $\begin{array}{l}\text { Applications include mapping terrain and, where laser } \\
\text { pulses penetrate the canopy, mapping canopy geometry } \\
\text { and biomass. }\end{array}$ \\
\hline
\end{tabular}

